\title{
Analysis on the Difficulties and Legislative Suggestions of the Proximate Causes of Insurance Law*
}

\author{
Sa Xiao \\ School of Art and Law \\ Wuhan University of Technology \\ Wuhan, China
}

\begin{abstract}
As an important principle of the insurance law, the principle of proximity is of great significance for determining whether an insurer should assume insurance liability. With the development of China's insurance business, the principle of proximity has gradually been adopted in judicial practice and insurance practice, in order to accurately grasp the principle of proximity, and apply it to the practice of insurance claims in China. This paper will discuss the concept of the principle of the proximate cause and propose methods and standards for the determination of the proximate cause and the proximate cause in different situations. At the same time, through the analysis of the cases of the proximate principle in the insurance trial in China, the problems and causes of the application of the proximate principle in judicial practice are found out, and corresponding suggestions are put forward to solve the above problems.
\end{abstract}

Keywords-proximate cause principle; insurance law; causality; judicial application; legislative advice

\section{INTRODUCTION}

As one of the four principles of the insurance law, the Chinese Insurance Law and the Maritime Law only reflect the spirit of the principle of proximity in the relevant provisions without explicit provisions, but in the insurance practice, it is judged whether the insurer bears The important basis of insurance liability, the lack of statutory law led to the suitability of insurance claims in the event. The Chinese judicial practice community has also noticed this problem. The application of the principle of proximate cause in the practice of claims has been reported. In 2017, 158 judgments have involved the principle of proximity. It can be grouped into three categories, one cause and one fruit, mostly due to continuous occurrence. Therefore, it is necessary to make an in-depth summary of the specific application status of the principle of proximity in China's judicial practice, and provide legislative support for the practical application of the principle of proximity.

\section{OVERVIEW OF THE PRINCIPLE OF PROXIMITY CAUSE}

In the 19th century, the British insurance industry, especially marine insurance, flourished, and various problems in claims were followed. In order to deal with various problems in claims, the principle of proximity has emerged and gradually developed into an important principle in insurance law. More than a hundred years ago, a British judge wrote in a judgment: "You don't have to be plagued by those far-reaching factors, or metaphysical distinctions between reasons of effectiveness, important causes, and cause of results; you only need to focus on those directly causing losses. The closest cause of the occurrence.[1] The Principle of Proximate Cause[2] is the basic criterion for judging the causal relationship between the underwriting risk and the loss of the insurance subject in the insurance claims, and thus determines whether the insurer should bear a standard of payment obligations.

\section{A. Concept of the Principle of Proximity Cause}

Before defining the concept of the principle of proximity, we should first understand the meaning of the term "proximate cause". The term near factor is used as an exotic product, and there is no corresponding vocabulary in Chinese. The proximate cause is derived from the legal term "Causa Proxima et Non Remota Spectatur"[3] which mean the closest reason in time and order. The continuous application of the principle of proximity in the practice of the AngloAmerican case law countries has greatly enriched the connotation of the term "proximate cause" and made it more and more difficult to define. The theoretical and practical circles at home and abroad have tried various definitions of what is a "proximate cause", but have never formed a widely recognized concept. At present, a more general definition: the proximate cause refers to the most direct, most effective and decisive cause of loss and the loss of risk, and does not refer to the closest reason in time or space. This definition combines the strengths of various definitions to form a more complete definition. However, the concepts of words such as "direct", "effective" and "decision" are still not precise enough, which makes it difficult to judge what the cause in practice is.

Because of the different understanding of the meaning of the term "proximate cause", scholars have also made various expositions on the concept of "proximate cause". There is not much disagreement among scholars on the understanding of the nature of the principle of proximity. According to the 
definition of the concept of "proximate cause" above, the principle of the proximate cause of the insurance law is among the many causes of the damage, if the most direct, most effective and decisive cause of the loss is the risk of underwriting. Then the insurer should bear a basic principle of insurance liability. It can be seen that the principle of proximity is an important principle concerning the issue of insurance claims, and it is an important criterion for judging whether an insurer should bear the liability for insurance.

\section{B. Analysis of the Theory of Proximate Cause and the Theory of Causality in Civil Law}

The principle of proximate cause in the insurance law is closely related to the theory of causality in civil law. The principle of proximate cause is established to some extent on the basis of causal theory. Therefore, some scholars in the civil law system only recognize the principle of the proximate cause in the broad sense, that is, the principle of the proximate cause of the insurance law is equivalent to the theory of causality in the civil law. The author believes that this view is not appropriate. First of all, as a special law of commercial law, the insurance law has its own particularity in both theory and practice. The theory of causality in civil law cannot satisfy its needs, and it is difficult to be an important criterion for judging whether an insurer should bear insurance liability. Secondly, the determination of causality in the insurance law is subject to the contractual agreement between the parties, and should pay attention to the reasonable expectation of the parties due to the contract [4].

1) Discrimination of the principle of proximity and the causal relationship: The theory of causality is the mainstream doctrine of causality in civil law countries. Its meaning is: Among the several conditions that cause damage, if a condition effectively increases the objective possibility of damage, it can be regarded as a sufficient condition for damage. Although both are discretionary by judges on causality, there is still a certain difference between the two. First of all, in terms of connotation, the principle of proximity causes the judgment of the near cause is whether a certain factor plays the most direct, effective and decisive role in the damage result. What is considered by the theory of causality is that which of the many reasons increases the objective possibility of the result. In the method of judging, the principle of proximity should consider more reasons for the force and driving force of the result, and the theory of causality is more about the probability of the result. The judgment of the principle of proximity is more certain, while the theory of causality is more dependent on probability. It can be seen that there is still a certain difference between the two.

2) Discrimination of proximate cause and proportional causality: The proportional causality theory was proposed by Japanese scholars. The proportional causality theory emphasizes that the proportion of the force of each cause to the loss result should be determined based on objective facts [5]. There is a breakthrough in the traditional theory of causality. It advocates that the judgment of causality no longer adopts the viewpoint with or without, but judges the proportion of the effect on the result according to the factual relationship, and then determines the proportion according to the proportion. Proportional causality theory reduces the cost of litigation in the long run because it is not necessary to select one of several reasons [6]. However, in fact, the proportional causality theory solves the problem that the insurer's compensation amount is determined in the case of multiple damage caused by the joint failure. It does not solve the problem of how to determine the near cause and how to determine whether the insurer should pay. Therefore, there is still a fundamental difference between the two.

\section{THE SPECIFIC APPLICATION OF THE PRINCIPLE OF Proximate CAUSES IN JUdicial PRACTICE IN CHINA}

After a long period of development, the principle of the proximate cause has become the mainstream principle for judging causality in the field of insurance law in the AngloAmerican legal system. Although there is no clear provision in the "Insurance Law" in China, the insurance law community generally recognizes the significance and status of the principle of proximity. China's insurance practice also applies the principle of proximity to the extent and extent. It is. According to incomplete statistics, in 2014, 241 insurance judgments used the principle of proximity, and in 2015, 287 insurance judgments involved the principle of proximity. In 2016, 326 insurance judgments involved the principle of proximity, and 2017 ended. There are currently 158 judgments involving the principle of proximity. It can be seen that the principle of proximate cause has received more and more attention in judicial practice.

\section{A. Applicable Rules of the Principle of Proximity in Judicial Practice}

Since the principle of the proximate cause, especially the concept of "proximate cause", is difficult to grasp and is unpredictable, in order to regulate the application of the principle of proximate cause in practice and guide the judge to decide the case, it is necessary to determine some operational and high recognition and applicable rules. Fortunately, a series of such general rules of practicality have emerged in the course of long-term insurance practices and insurance jurisprudence.

1) Applicable rules in the case of one cause: This situation means that the damage result is caused by a single cause. In this case, the factual relationship is relatively simple, and the determination of causality is relatively simple. If the single cause of damage is the risk of contracting, the insurance company should assume insurance liability. However, if the reason is excluded risk or exemption, the insurance company does not assume insurance liability. Whether the insurance company assumes the insurance liability is the key to determining whether the exemption clause is a near cause, and the insurer is responsible for the exemption. 
2) More applicable rules for continuous occurrences: This situation refers to the fact that the insurance damage result is caused by two or more reasons, continuous natural and no other factors involved in the continuous occurrence. In this case, the latter is a natural and reasonable continuation of the antecedent, and the occurrence of the antecedent will inevitably lead to the occurrence of the cause. Therefore, we usually regard the antecedent as the decisive factor, that is, the "proximate cause", and the latter is regarded as the medium of the cause transmission.

If the risk of underwriting is caused before the cause of the failure, the insurance company should assume the insurance liability regardless of whether the cause is the underwriting risk. If the former cause is not contracted, then even if there is an underwriting risk in the latter, the insurance company will not bear the insurance liability. It is worth noting that if the cause of continuous occurrence is interrupted, that is, how to determine whether the insurer should pay if there is an intervention factor. If the previous cause chain is severed by a new intervention factor and the intervention factor is relatively independent and unaffected by the antecedent then it should be judged based on the nature of the interventional factor. If the intervention factor is a contracting risk, the insurance company should assume the insurance liability and vice versa.

3) More applicable rules due to co-occurrence: This situation refers to the fact that the damage result is caused by a combination of multiple causes. The co-occurrence of multiple reasons does not require multiple causes to occur at the same point in time. It is more important that there is no causal relationship between multiple causes and thus is different from multiple occurrences. In this case, due to multiple reasons at the same time, it is difficult to judge what the cause is according to the principle of proximity.

If the multiple reasons are all the underwriting or the risk of exclusion, the relative judgment is simple. If the risk is covered, the insurer shall bear the insurance liability. If the risk is excluded, the insurance liability will not be borne. The more difficult is the combination of multiple risks and exclusion risks. Some scholars believe that the exclusion of risk is preferred. When there are both exclusionary risks and underwriting risks in multiple risks, the exclusion liability is given priority, and the insurer does not assume insurance liability. However, this view is not conducive to the protection of insurance counterparts, and the insurance expectation of the insurer is relatively frustrated. Another point of view is that underwriting risks take precedence and insurers should assume insurance liabilities. However, this view adds to the insurer's responsibility and is also prone to moral hazard. Some scholars have proposed to allocate according to the average number of reasons. "For example, there are three accidents, one of which is an insurance accident and two are the exclusion accidents. The insurer should compensate for one-third of the losses. [7]"

We believe that in this case, we can learn from the proportional causal relationship and combine the principle of fairness. The judge judges the force of different factors to determine the proportion of the insurance company's losses. The Judicial Interpretation of Insurance Law (3) also supports this kind of practice. At present, there are already practices in the judicial practice of using proportional causality to conduct judicial precedents, such as the case of Lu Pingyi v. Meiya Property Insurance Co., Ltd and the case of personal insurance contract disputes of the company's Shanghai branch. Of course, we still need to set standards to prevent judges from excessive discretion.

\section{B. Allocation Principle of Burden of Proof}

In the current laws and regulations, there is no special provision for the burden of proof of the principle of proximate cause, so the provisions of the Civil Procedure Law and related laws and regulations on the burden of proof should be applied. According to the principle of proof of who advocates who gives evidence, and the provisions of the first paragraph of Article 22 of the Insurance Law, "the insured, the insured or the beneficiary shall provide the insurer with the evidence and information they can provide", and the insured shall The insured or the beneficiary shall first give evidence of the insurance liability, but the scope of the certificate shall be limited to the certificates and materials it can provide. This means that the insured, the insured or the beneficiary will only bear the initial burden of proof. If the evidence is difficult, the burden of proof will be reversed or the insurer will provide a counter-evidence to prove that the near-end is an exclusionary risk. Otherwise, it bears the unfavorable consequences of the proof. This rule not only conforms to the provisions of the Civil Procedure Law, but also takes into account the principle of fairness and prevents disadvantages of insurance counterparts who are in a disadvantaged position.

\section{The Status Quo, Causes and Suggestions of THE PRINCIPLE OF PROXIMATE CAUSES IN JUDICIAL PRACTICE IN CHINA}

As a key principle in the insurance law, the principle of the near cause plays an important role in judging whether the insurer should bear the insurance liability. In recent years, it has received more and more attention from judges in practice and has been widely used in practice. However, in practice, the application of the principle of the proximate cause has various problems, which leads to its failure to give full play to its due role. Instead, it has reduced efficiency and caused various controversies.

\section{A. Analysis of the Status Quo and Causes of the Principle of Proximate Causes in China's Judicial Practice}

1) The understanding of the concept of the principle of proximity is different: Although the current judicial judges judge a wide range of referees based on the principle of proximity, the concept of the principle of the proximate cause is different. Some people think that the principle of the proximate cause is the special concept of the insurance law and apply the applicable rules of the principle of the proximate cause. Some think that the principle of the proximate cause is the theory of causality in civil law, and 
the reasoning is based on causality. And some use the inevitable causal relationship, some use the theory of causality, and some directly apply proportional causality to directly determine the proportion of claims.

2) The scale of the referee is different and the results are too different: In the case of refereeing using the principle of proximate cause, especially because of the cooccurrence of cases, the identification of the near cause is difficult. It is necessary for the judge to determine whether the insurance company should bear the insurance liability and determine the proportion of the compensation. It is necessary for judges to make extensive use of discretion and to make judgments based on their own social experience, resulting in different judgment standards. The same type of case or even the same case has excessive judgment results.

3) Analysis of the reasons for the above conclusions: The main reasons for the above results are as follows: First, For the principle of proximate cause, there is no clear legal provision in China, which leads to the lack of uniform standards for the use of judges in the trial of cases. Second, the theoretical research on the principle of the near cause has not yet been deepened. The principle of the near cause belongs to the imported goods. The time of introduction to China is still short. At present, the academic circles cannot theoretically form a unified general theory about the principle of the near cause. Moreover, the mechanical introduction of the principle of the near cause cannot adapt to China's national conditions, leading to the theory falling behind practice.

\section{B. Suggestions on Perfecting China's Proximate Principle System}

In order to solve the problems that apply to the principle of the proximate cause in practice, and to improve the application of the principle of the near cause in practice, the following suggestions are made for improving the proximate system of China:

1) The principle of proximity is clearly defined in the law: As a key principle in the insurance law, the principle of the near cause has been widely applied in practice, but it is faced with an embarrassing situation that is not clearly defined in the law. Therefore, it is indeed necessary for China to introduce the principle of proximity into the Insurance Law. First of all, because China's current theoretical circles still have controversy about the concept of the principle of the near cause and the applicable rules, and the judgment of the near cause is more discretionary, the principle of the near cause should be principled. Provisions. This will not only solve the problem that cannot be relied upon, but also leave room for future theoretical development. Secondly, the specific location of the principle of proximity in the law. The author believes that although the principle of proximity is an important principle in the insurance law, it has not become the basic principle of the entire insurance law as the principle of loss filling and the principle of maximum good faith, so it should not be stipulated in the general part. It should be specified in the sub-section.

2) Strengthening theoretical research on the principle of proximity: The principle of proximity is a very complex and esoteric theory that requires us to continue to study it. At present, the research and application of the principle of the near cause in the theoretical and practical circles of our country still mostly stay at the level of transplantation and reference to the traditional theory of the principle of the common law. We need to be rooted in China's insurance practice, and conduct in-depth research on the theory, so that the principle of proximity applies to the actual situation of China's insurance industry, guide the judicial practice of the principle of proximity, and guarantee the sustainable and healthy development of the insurance industry.

3) Publish guiding cases on the principle of proximity: The revision of the law and the study of the theory require a long process and cannot solve the urgent need. The case guidance system can effectively make up for the deficiencies of judicial interpretation. It has the meaning of protecting the referee, regulating the discretion of judges, and ensuring the accurate application of the law. Therefore, it is necessary to solve the problem that the judges have different standards and scales in the trial of cases using the principle of proximate cause and have great differences in conceptual understanding. The guiding cases can be effectively resolved through the issuance of guiding cases by the Supreme People's Court.

\section{CONCLUSION}

In the insurance legal relationship, the insurance party is most concerned about the insurer's insurance liability and is also the core content of the insurance contract. The use of the principle of proximity to identify insurance liability can not only fully balance the interests of insurance parties, but also promote the healthy development of the insurance industry. Therefore, it is necessary to make an in-depth summary of the specific application status of the principle of proximity in China's judicial practice. In the Insurance Law, the principle of the proximate cause is stipulated, and the guiding rules for the principle of the proximate cause are further elaborated through the issuance of guiding cases by the Supreme People's Court. In order to make up for the loopholes in the legislation on the principle of proximity, and provide legislative support for the practical application of the principle of proximity, the principle of proximity should be universally applied and accurately applied in practice

\section{REFERENCES}

[1] Ionides v. The Universal Marine Insurance Co.(1863) 14CB(NS)259, 289.

[2] Lloyd's List Law Reports, Vol.18. No.7.

[3] William Gow, M. A, PH. D. Sea Insurance [M], 1877: 306. 
[4] Peter Nash Swisher, "Causation on Requirements in Tort and Insurance Law Practice: Demystifying Some Legal Causation" Riddles'", 43 Tort Trial \& Ins. Prac. LJ, 1 (2008).

[5] York shire Dale Steamship Co. Ltd. v. Minister of War Transport, (The Coxwold) [1942] AC691, 713.

[6] Erik S. Knutsen, Confusion about Causation in Insurance: Solutions for Catastrophic Losses, 61 Ala L. Rev. 1011 (2010).

[7] Howard Bennett. The Law of Marine Insurance [M]. Social Science Electronic Publishing, part 6Principles of Causation, P. 